\title{
An experimental study of the air humidification process using a membrane contactor
}

\author{
Sebastian Englart ${ }^{1, *}$ \\ ${ }^{1}$ Wrocław University of Science and Technology, Faculty of Environmental Engineering, Department \\ of Air Conditioning, Heating, Gas Engineering and Air Protection, 4/6 Norwida st., 50-373 Wrocław, \\ Poland
}

\begin{abstract}
The article presents the results of the experimental examination of the effectiveness of air humidification using a membrane module. The construction of the membrane module and the measuring stand is also discussed. In order to assess the effectiveness of air humidification using the membrane module, the measurements of temperature and humidity at the membrane module's inlet and outlet, air flow rate, water flow rate and water temperature were taken. Based on the measurements, the effectiveness coefficients, $E$, have been determined. The power demand for the solution under study has also been discussed.
\end{abstract}

\section{Introduction}

The humidification of air in air conditioning is accomplished using either steam or water. While steam humidification is conducted using steam humidifiers, in the case of using water, there are three basic air humidification methods:

- air flow through a spray chamber, where water is sprayed with nozzles; humidification takes place upon the direct contact of air with the sprayed water,

- air flow over the wetted surface - this method is employed in evaporative humidifiers (e.g. in chambers with sprinkled surfaces),

- spraying water to form aerosol-size droplets (of a diameter of approx. $5 \mu \mathrm{m}$ ) either directly in the room or in the channel supplying air to the room - the air humidification method, whereby the sprayed water is completely evaporated and the air is adiabatically cooled, is accomplished using pneumatic nozzles, high-speed rotary discs, or ultrasounds.

Central air humidification devices used include spray chambers and sprinkled surface chambers, which in turn include fixed and movable sprinkled packing chambers $[1,2]$.

In addition to commonly used solutions for conducting air drying, humidifying or evaporative cooling processes, also membranes can be used [3]. For this purpose, chiefly synthetic membranes are utilized, which make a porous semipermeable barrier between the liquid and the air.

The use of membranes for air treatment can offer the following advantages, compared to traditional air treatment techniques [4-8]:

- no direct contact between the liquid and the air,

* Corresponding author: sebastian.englart@pwr.edu.pl 
- elimination of liquid droplets from the air stream,

-due to the small sizes of its pores, the membrane prevents microorganisms, bacteria or spores from passing from one phase to another,

- a membrane prevents the contamination of the liquid with airborne dusts,

- a membrane provides a large exchange surface relative to the occupied space,

- good efficiency,

- low friction losses, both on the air and liquid sides.

The article has reported the results of the experimental examination of the effectiveness of air humidification using a membrane module.

\section{Evaluation criteria}

There are few evaluation criteria that can be used for comparing air humidification devices and processes. This can be for example humidification effectiveness, temperature effectiveness, average moisture permeability or electric power demand index.

\subsection{Process effectiveness}

The effectiveness of a process can be defined as the ratio of the actual process to the theoretical process. With contact between air and water in an ideal exchanger with an infinitely large surface area, the theoretical quantity of sensible heat exchanged in the system can be written as:

$$
Q_{S, t}=m_{a} c_{p a}\left(t_{1}-t_{w 1}\right)
$$

In a real exchanger, the quantity of exchanged sensible heat will be:

$$
Q_{S}=m_{a} c_{p a}\left(t_{1}-t_{2}\right)
$$

This results in the effectiveness, $E_{t}$, defined as a dimensionless index:

$$
E_{t}=\frac{Q_{S}}{Q_{S, t}}=\frac{t_{1}-t_{2}}{t_{1}-t_{w 1}}
$$

This coefficient can be defined as the temperature effectiveness. Similarly, for the latent heat associated with the exchanged mass flow, it can be written as follows:

- theoretical:

$$
Q_{L, t}=m_{a} r\left(x_{w 1}-x_{1}\right)
$$

where: $x_{w 1}$ is equal to the air moisture content at the water temperature. - actual:

$$
Q_{L}=m_{a} r\left(x_{2}-x_{1}\right)
$$

So, the effectiveness, $E_{x}$, will take on the following form:

$$
E_{x}=\frac{Q_{L}}{Q_{L, t}}=\frac{x_{2}-x_{1}}{x_{w 1}-x_{1}}
$$


This coefficient can be defined as the humidification effectiveness.

In the above equations:

- index 1 refers to the parameters of air at the inlet,

- index 2 refers to the parameters of air at the device's outlet,

- index $t$ denotes ideal (theoretical) conditions,

$t$ - air temperature, $\mathrm{K}$,

$t_{w}$ - water temperature, $\mathrm{K}$,

$x$ - moisture content, $\mathrm{kg} / \mathrm{kgs} . \mathrm{p}$.,

$m_{a}-$ air mass flow rate, $\mathrm{kg} / \mathrm{s}$,

$c_{p a}-$ specific heat of air, $\mathrm{J} /(\mathrm{kgK})$,

$r$ - heat of vaporization, $\mathrm{J} / \mathrm{kg}$.

Studies $[9,10]$ define efficiencies in a similar manner. That being said, the temperature effectiveness is described as the sensible cooling effectiveness. Another effectiveness indicator can be the average moisture permeability, which is determined as [11]:

$$
P e=\frac{m_{a}\left(x_{2}-x_{1}\right)}{A_{t o t}}
$$

Where: $A_{\text {tot }}-$ total area of the fiber outer surface, $\mathrm{m}^{2}$.

Effectiveness is sometimes called efficiency and can be expressed in per cents.

\subsection{Power demand}

When selecting an air humidification method, in addition to the criterion of effectiveness or efficiency that can be achieved by that humidification method or a specific device, the power demand or energy consumption of this specific solution must be taken into account. Comparison of different air humidification devices can be made, for example, based on the electric power demand index as related to the quantity of sprayed water or steam. Basic energy expenditures associated with the operation of a membrane humidifier result from the transfer of air and water. Hence, the demand for electric power needed for air transfer can be expressed by the formula below:

$$
N_{a}=\frac{m_{a} \Delta p_{m}}{\rho_{a} \eta}
$$

For the pump water transfer system:

$$
N_{w}=\frac{m_{w} \Delta p_{p}}{\rho_{w} \eta}
$$

$m_{w}-$ water mass flow rate, $\mathrm{kg} / \mathrm{s}$,

$\Delta p_{m}$ - pressure drop in the flow of air through the membrane module, $\mathrm{Pa}$,

$\Delta p_{p}$ - pump delivery head, $\mathrm{Pa}$,

$\rho$-density, w-water, a-air, $\mathrm{kg} / \mathrm{m}^{3}$,

$\eta$ - device efficiency.

The total electric power demand for the operation of air humidification with the membrane module will be:

$$
N=N_{a}+N_{w}
$$

By relating the above power demand for the humidification degree, $W_{x}$, we can determine the relative power demand:

$$
n=\frac{N}{W_{x}}
$$


where:

$$
W_{x}=P e A_{t o t}
$$

The index $n$ can be used for comparing different types of air humidifiers.

\section{Experimental setup}

Tests of the air humidification process using the membrane module were carried out on a test stand (Fig. 1), which enabled the measurement of:

- ambient air temperature and humidity,

- temperature and humidity of air at the membrane module's inlet and outlet,

- air flow rate in the channel,

- temperature of water upstream/downstream the module,

- water flow rate.

For making the membrane module, a polypropylene (PP) capillary membrane with the following parameters was used:

- membrane inner diameter, $1.67 \mathrm{~mm}$,

- membrane outer diameter, $2.71 \mathrm{~mm}$,

- average pore size, $0.43 \mu \mathrm{m}$,

- maximum pore size, $0.55 \mu \mathrm{m}$.

In the module, 744 membranes of a total surface area of $3.04 \mathrm{~m}^{2}$ and a specific surface area of $667 \mathrm{~m}^{2} / \mathrm{m}^{3}$ were used. The membranes were situated perpendicularly to the air flow direction.

Measurements were taken for variable air and liquid flows. For air, the flow was varied within the range of $60-120 \mathrm{~m}^{3} / \mathrm{h}$, while for water, within $100-400 \mathrm{l} / \mathrm{h}$. Examples of air transformation in the test installation are shown in the $i-x$ diagram (Fig. 2). Transformation 1-2 was accomplished in the heater, while transformation $2-3$, in the membrane module. 


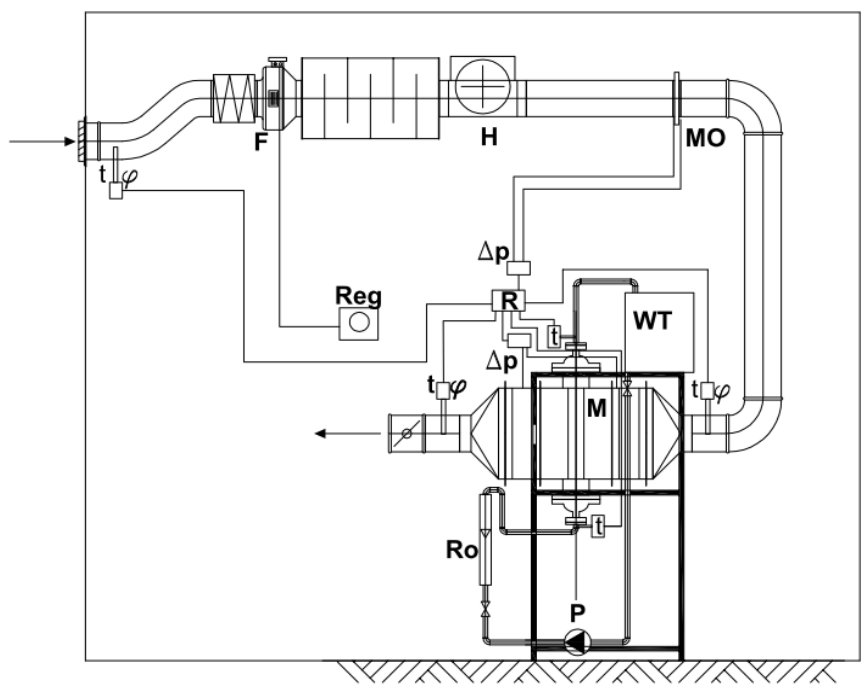

Fig. 1. Schematic diagram of the measuring stand. F-fan, H-heater, MO-measuring orifice, Ro-rotameter, R-recorder, WT-water reservoir, M-membrane module, P-pump, Reg-thyristor controller, sensors of: t-temperature, $\varphi$-humidity, $\Delta \mathrm{p}$-differential pressure.

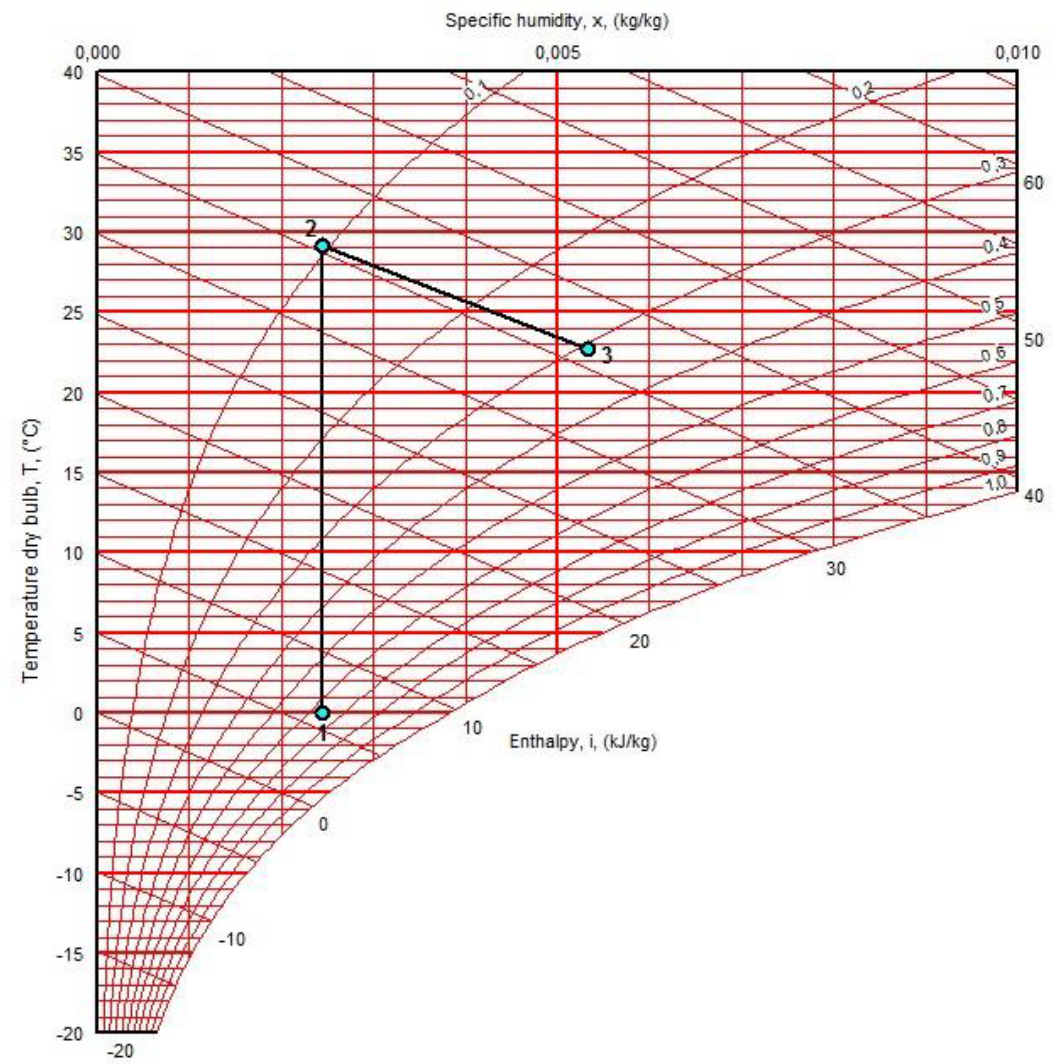

Fig. 2. Examples of air transformation in the experimental installation during air humidification. 


\section{Experimental results}

In order to assess the effectiveness of air humidification using the membrane module, the measurements of temperature and humidity at the membrane module's inlet and outlet, air flow rate, water flow rate and water temperature were taken. Based on the measurements, the effectiveness coefficients, average moisture permeability and the relative power demand have been determined.

\subsection{Effectiveness}

The values of the effectiveness coefficients were determined, respectively, form Equations (3) and (6). The percentage effectiveness coefficient values as a function of air flow rate are represented in Fig. 3. The average effectiveness $E_{t}$ within the examined air flow rate variability interval was $55.3 \%$. Changes in the flow rate of water and air flowing through the module did not cause any significant changes in temperature effectiveness. The average effectiveness $\mathrm{E}_{\mathrm{x}}$ amounted to $31 \%$. In this case, a slight decrease in humidification effectiveness with the increase in air flow rate was observed. Practically, no effect of variations in the flow rate of water flowing through the module on the air humidification effectiveness was found.

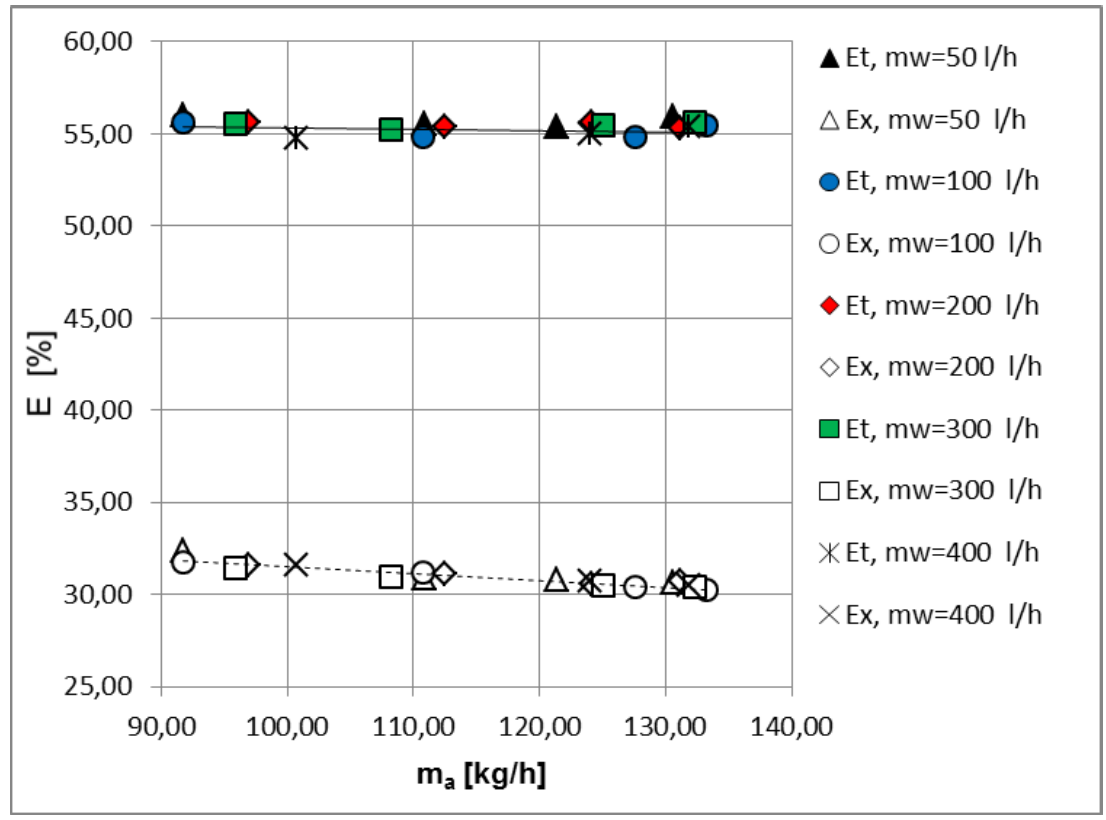

Fig. 3. Comparison of the effectiveness at varying water and air flow rates in the module. 


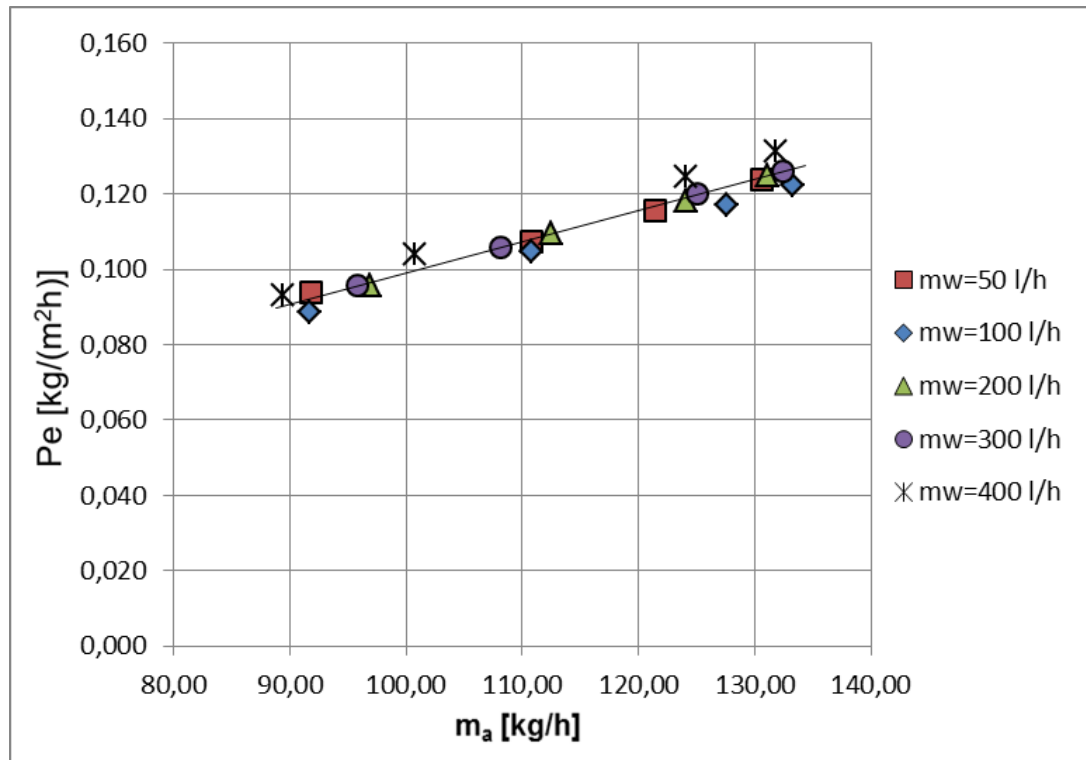

Fig. 4. The effects of air and water mass flow rate on the average moisture permeability of the module.

\subsection{Average moisture permeability}

The effect of variations in the flow rate of air and water flowing through the membrane module on the average moisture permeability value is illustrated in Fig. 4. With increasing air flow rate, the average moisture permeability increased.

\subsection{Relative power demand}

The relative power demands data for sample air humidifiers, provided in article [12], have been used to plot the diagram shown in Fig. 5. Four humidifiers were compared, including: a rotational humidifier, a pneumatic spray nozzle humidifier, and two steam humidifiers: with electric heaters and with immersed electrodes, respectively. The maximum relative power demand for the test module, as determined from Equation (11), amounted to $59 \mathrm{~W} /(\mathrm{kg} / \mathrm{h})$. This index has been obtained with maximum air and water mass flow rate, minimal humidification degree, $W_{x}=0,37 \mathrm{~kg} / \mathrm{h}$, and the total electric power demand $N=22 \mathrm{~W}$. Within these parameters the relative power demand was reduced by over $92 \%$ compared to steam humidifiers. 


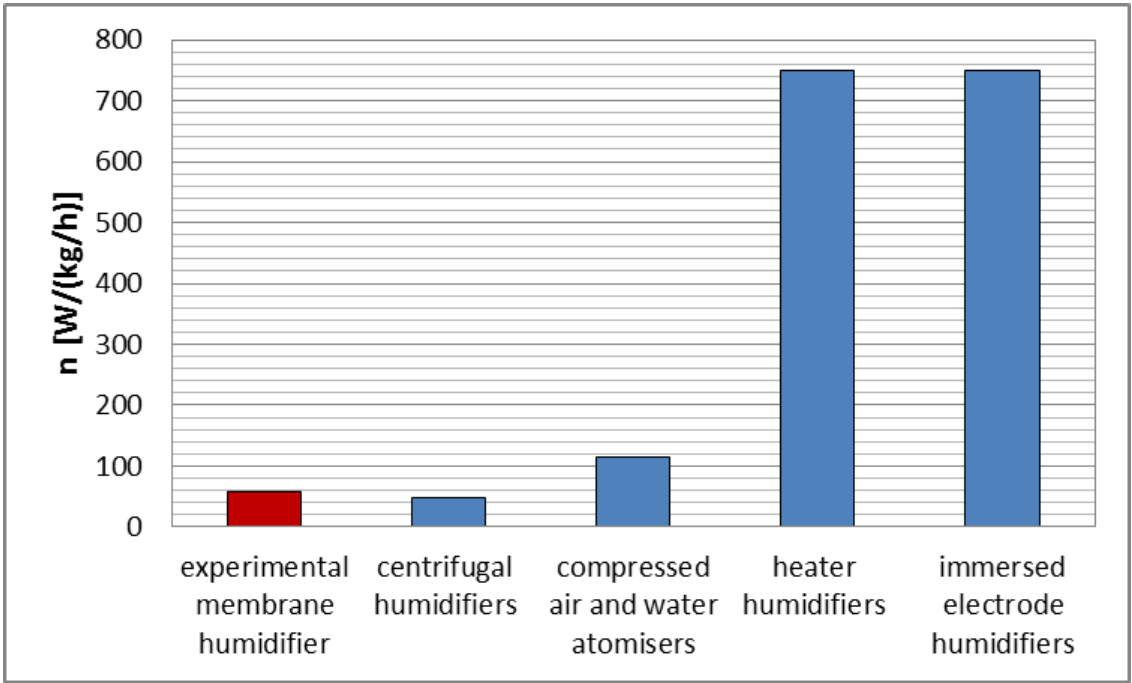

Fig. 5. Comparison of the relative power demand for different humidifiers.

\section{Conclusions}

Membranes are not commonly used for air treatment in air conditioning systems. However, by using them, the relative power demand could be reduced, compared to traditional solutions. The performed experimental tests have shown that the air humidification process can be conducted using a membrane module. Satisfactory effectiveness levels were achieved for the process carried out.

Membrane modules can find application in air conditioning technology as air humidification devices.

\section{References}

1. S. Englart, A. Kmieć, A. Ludwińska, Can. J. Chem. Eng. 87, 185-192 (2009)

2. A. Kmieć, S. Englart, A. Ludwińska, Can. J. Chem. Eng. 87, 163-168 (2009)

3. J. Woods, Renew. Sust. Energ. Rev. 33, 290-304 (2014)

4. S. Bergero, A. Chiari, Appl. Therm. Eng. 21, 1119-1135 (2001)

5. C. Isetti, E. Nannei, A. Magrini, Energ. Buildings, 25, 185-193 (1997)

6. D. W. Johnson, C. Yavuzturk, J. Pruis, J. Membr. Sci., 227, 159-171 (2003)

7. K. Kneifel K., S. Nowak, W. Albrecht, R. Hilke, R. Just, J. Membr. Sci., 276, 241-251 (2006)

8. P. Scovazzo, J. Burgos, A. Hoehn, P. Todd, J. Membr. Sci., 149, 69-81 (1998)

9. L.Z. Zhang, Z.X. Li, T.S. Zhong, L.X. Pei, J. Membr. Sci., 427, 1-9 (2013)

10. L.Z. Zhang, Int. J. Heat. Mass. Tran., 55, 5861-5869 (2012)

11. L.Z. Zhang, S.M. Huang, Int. J. Heat. Mass. Tran., 54, 1055-1063 (2011)

12. A. Ludwińska, S. Englart, A. Kmieć, COW, 39, 26-29 (2008) 